\title{
East-West Dialogue in Sophia Gubaidulina's Work “Tatar Folklore Inspirations": on the Problem of Artistic Bilingualism
}

\author{
Nadežda Velerovna Shirieva', Elena Aleksandrovna Dyganova ${ }^{2}$ \\ ${ }^{1,2}$ Kazan Federal University, 18 Kremlyovskaya street, Kazan 420008, Russia Federation. \\ Corresponding email: taha1978@mail.ru
}

Received May 15, 2017; Revised July 18, 2017; Accepted July 25, 2017; Published August 16, 2017.

\begin{abstract}
Sofia Gubaidulina, a living classic of modern music and one of the most popular composers of our time, is in constant search of both new timbres and spiritual truths. Born in Kazan (Russia), at the intersection of Tatar and Russian cultures as well as Islam and Christianity, she was naturally influenced by all of them, which is best reflected in Gubaidulina's continual interest in the wide range of expression means offered by Oriental music. This phenomenon led to a wide discussion among musicologists on a synthesis of Western and Oriental cultural traditions in Gubaidulina's music. However, Sofia Gubaidulina's music based on the pentatonic scale is one of the most poorly studied areas in her artistic legacy. It includes three cycles of pieces "Tatar Folklore Inspirations" for small, alto and bass domra with piano accompaniment analysed in this paper have specific modal and rhythmic features characterising Tatar traditional music. The author's approach to the problem of correlation of the "own" and the "alien" in the musical text of the triptych as an artistic dialogue between the ethnic and the pan-European is based on the theory of intertextuality, applied to analyse various parameters of intertextual communications in Gubaidulina's work. This study reveals how the composer identifies herself within different cultures and explains her "play of styles" as a new form of artistic synthesis integrating world art trends with ethnic cultural paradigms.
\end{abstract}

Keywords: domra, intertextuality, European, pentatonism, polystylistics, synthesis, Tatar music, artistic dialogue, ethnic.

\section{Introduction}

The 2oth century revealed the advent of a special musical expression, which demanded the invention of fundamentally different methods of work with audio material. The synthesis of ethnic music traditions with the constructive laws of Western European art became one of the ways to get new sounds for composers. Oriental music was especially attractive. V.N. Kholopova explains her interest in it with the progress of European music, which passed the way from the natural overtone series to microtonality and deepened into timbre realm, sonorism, non-metric rhythm in several centuries (Kholopova, 1999, p. 153).

(C) AesthetixMS 2016. This Open Access article is published under a Creative Commons Attribution Non-Commercial 4.0 International License (http://creativecommons.org/licenses/by-nc/4.0/), which permits non-commercial re-use, distribution, and reproduction in any medium, provided the original work is properly cited. For citation use the DOI. For commercial re-use, please contact editor@rupkatha.com. 
C. Debussy, M. Ravel, D. Milhaud, F. Poulenc, H. Villa-Lobos, O. Messiaen started the experiments on the introduction of characteristic elements of oriental musical language into the composition. Then they were continued by H. Cowell, Ch. Ives, J. Cage. Sofia Gubaidulina's name stands alongside the names of the composers mentioned above. Having absorbed all the trends of contemporary compositional techniques, she also did not escape the attraction to Oriental music, which was inevitable in her case. Born from the union of a Tatar father and a Russian mother in the province, where two nations lived and two religions were closely intertwined, she could not help but be influenced by the different mentalities. Such a cultural fusion influenced the creative work of other composers of Tatarstan, which is described by R.C. Khurmatullina (Khurmatullina, 2014) and E.V. Kovrikova (Kovrikova, 2016). Most likely, that was what determined the specific "orientality" of S. Gubaidulina's music, in which the characteristic features of Western music, such as clarity, constructiveness and clear adherence to the narrative logic, interweave with the typical features of Oriental art, which include contemplation, variation and improvisation (Kholopova, 1991, p. 36).

Researchers of Sofia Gubaidulina's work have always been interested in the problem of organic coexistence of Western and Oriental "speech elements" in her musical language (Note 1). This problem is raised in the works of such Russian scholars as V. Kholopova (Kholopova, 1999), A.Yu. Kudryashov (Kudryashov, 1990), the Chinese musicologist B. Gan' (Gan', 1997), the American researcher Fay Damaris Neary (Neary, 1999).

Despite the connection with the East, which can be felt in many of S. Gubaidulina's works, there are few works based on the Tatar pentatonic motives in her artistic heritage. These are the three cycles of five pieces for domra "Tatar Folklore Inspirations" (1977), three pieces for two trumpets - "Tatar song", "Holiday", "Suyumbika" (1979), the soundtrack to the Tatar film "Threeday holiday" (1979) and "Tatar dance" for bayan and two contrabass (1992). A short list of works, in which S. Gubaidulina refers to the Tatar pentatonism, led to a very small number of studies devoted to her music with the national colour.

These include works of I.R. Basharova (Basharova, 2008) and Sh.Kh. Monasypov (Monasypov, 2014), in which the attention of the researchers was focused on the musical and sign aspect of S. Gubaidulina's "Tatar" works (I.R. Basharova) and their interpretation from the perspective of spiritual studies (Sh.Kh. Monasypov). Also, G. Mukhametdinova (domra) and Yu. Sokolskaya (piano), the first performing musicians of "Tatar Folklore Inspirations", released the guidelines that combine the analysis of the figurative aspect of the pieces with practical instructions on the specifics of execution (Mukhametdinova and Sokolskaya, 2013).

However, the tasks of these authors did not include tackling the problem of finding original artistic dialogue between the ethnic and the European in the works. Since the ethnic is already "given" by the pentatonism, then the models of this dialogue will be built mainly on the basis of a single parameter of textual bilingualism, i.e. different forms of relations of pentatonism and "extended tonality".

The allocated problem of correlation of the substantial basis of ethnic music culture and the European composer logos in S. Gubaidulina's works resulted in the search for appropriate methodology. Agreeing with J. Lochhead that the latest music requires an approach to the study that corresponds with its changeable state, we consider the theory of intertextuality, established in the depths of cultural linguistics, the most appropriate, especially, its interpretation by M.G. Aranovskiy (Aranovskiy, 1998), in which the scholar puts the emphasis on the process of transformation of the "alien" (borrowed) into the "own" (original). This study will focus on the 
analysis of intertextual links of this kind in “Tatar Folklore Inspirations”, the first S. Gubaidulina's opus, where she pays tribute to her Tatar roots.

\section{Discussion and Results}

The main constructive element of the musical fabric of this work is the pentatonic scale of major and minor mood, which the composer subjects to different transformations, using three basic principles - folklore stylization, polystylistics and chromatization.

\section{The principle of folklore stylization}

S. Gubaidulina gives a significant role to the stylization of the sound of Tatar folk songs and tunes. You can hear a free folk tune of kurai (the first piece of the first cycle), secret tunes of munajat (alto domra solo in the first part of the second cycle), an imitation of the tanbur sound (the Note 2) (bass domra party in the first piece of the third cycle). The monologue of small domra in the third piece of the first cycle and the thematism of the third piece of the second cycle are penetrated with epic intonations, referring us to the ancient genre of baits. The same part of the final cycle is marked with vintage of the melodic material of the bass domra solo. Pizzicato used together with glissando and vibrato creates a meditative mood, immersing the listener into the sacred environment of each sound.

However, using the above-mentioned pieces anhemitonic modal structures, S. Gubaidulina is not confined to the absence of semitones. She destroys its archaic sound, sprinkling it with bright "flashes" of chromatic sounds (cycle 2, piece 1), then following the path of the multimodal combinations of fragments of pentatonic scales of major and minor moods, while deliberately avoiding the explicit definition of the modal colouring (cycle 2, piece 3), or breaking concentrated pentatonic space with the "shimmer" of pentachords or chromatic cluster accords (cycle 1, piece 2; cycle 3, pieces 1 and 3).

Another type of stylization in the cycles "Tatar Folklore Inspirations" is the imitation of musical instruments belonging to the folk traditions of other nations. For example, in piece IV of the first cycle the sharp tone of domra resembles the sound of balalaika, and fast tempo and tremolo can be associated with the manner of execution of Russian dance tunes.

In this episode S. Gubaidulina achieves tart sound colour by matching anhemitonic scale of minor inclination of gis with perfect $a-d$ fourth. The approach to the climax is characterized by increasing tension. Folk colourfullness of the vertical structure gives the way to sonority, enhanced by the contrast of whirling chromatic intonations of domra and bourdron sound of grand piano in contra octave, which are sequenced up. The culmination itself is the execution of glissando up and down the tritons during several bars, finishing with the "slipping" of sound. It is a kind of sound symbol of Sisyphean labour, which appears in many S. Gubaidulina's works (Kholopova, 2015).

In a number of pieces we can find the echoes of Spanish folk music. So, S. Gubaidulina uses domra as the equivalent to Spanish guitar. The characteristic methods of sound production, rhythmic pattern, the manner of execution create a vivid impression of guitar performance. For example, in piece $\mathrm{V}$ of the first cycle the acciaccatura of two notes before epy harmonic sixth sounds like a slow version of the arpeggio (Note 3). The composer refuses the pentatonic scale of the domra part: the expressive lyrical melody sounds in the upper register of natural E major. 
Doubling it into the sixth, the rhythmic pattern consisting of triplet quavers and duplet quavers all these features of execution refer us to the genre peculiarities of Spanish music (dances, serenades, romances) (Note sheet example 1).

\section{Note sheet example 1. S. Gubaidulina “Tatar Folklore Inspirations”,} piece V from "Five pieces for bass domra and piano"
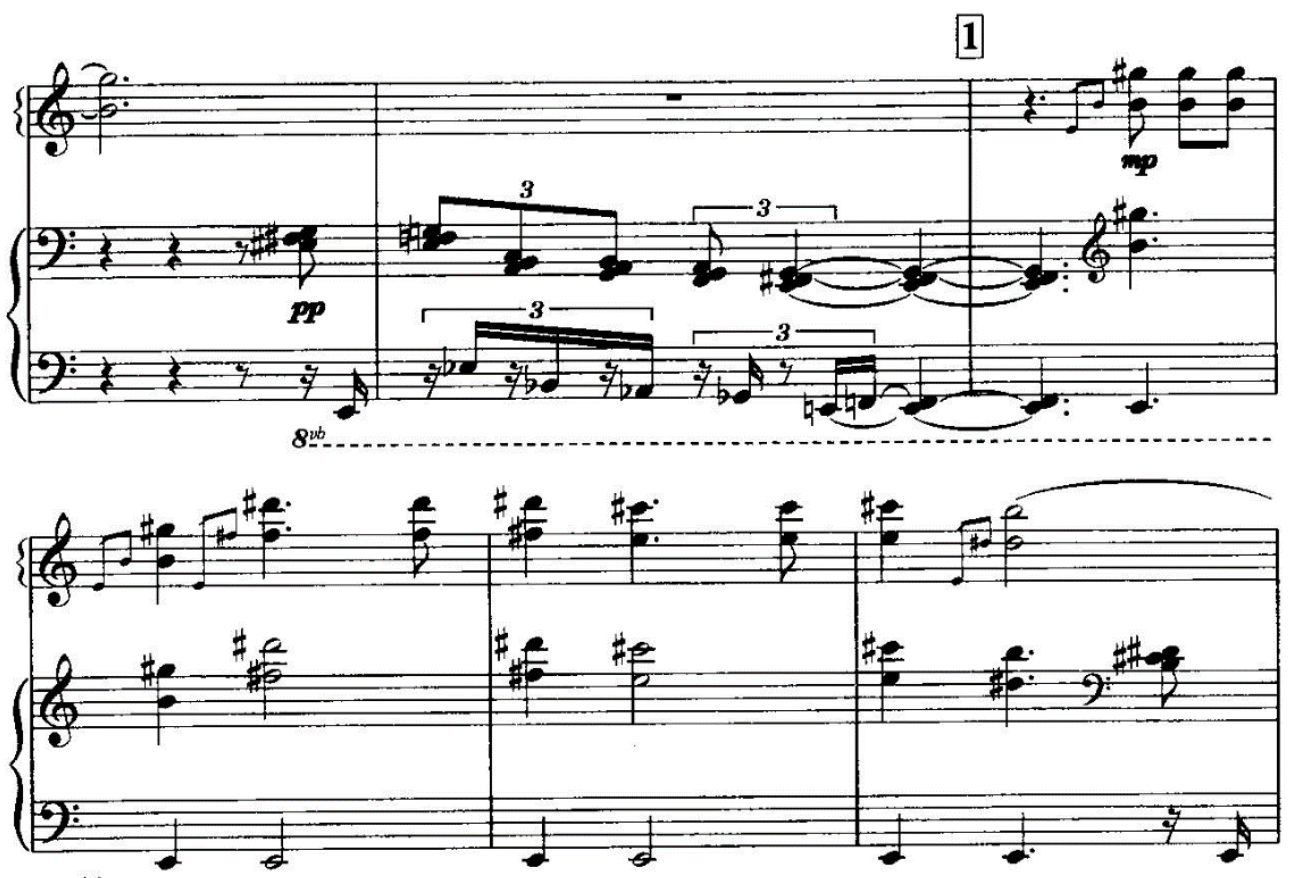

$(8)$

In this play S. Gubaidulina uses her favorite principle of building musical drama - the principle of contrast - which is expressed in this case with contrasting consonance and dissonance, diatonicism and chromaticism, the upper and the lower registers. Bright, measured, almost idyllic domra phrases are interspersed with chaotic piano remarks in the lower register, characterized by a "ragged" rhythm, downward movement and sharply sounding cluster accords. In this opposition we can clearly notice the symbol - the peace of eternity and the vanity of caducity, temporality and intemporality, the sublime and the mundane.

Piece II from the second cycle is an allusion to the genre of flamenco. This is evidenced by the changing meter $(5 / 8,4 / 8,3 / 8,6 / 8)$, asymmetrical, quasi-syncopated rhythmic pattern of leading domra. The basis of the repeated motivic link is the intonation of the forth (clean and enlarged), which is the material for constructing the chord vertical structure. There is no explicit anhemitonic structure in the play. However, it becomes apparent in the structure of non-altered piano clusters. If we arrange them horizontally, we will be able to detect consecutive fifths, which is characteristic of the absence of semitones. The development is done by sequencing a given motivic segment up the semitones, then the parts of both instruments begin to interact in the technique that slightly resembles a mensuration canon: a clear fourth "dripping" of quavers of piano time value is opposed to the stringy "chant" of the same interval of domra. The part finishes with the meditative swinging of the fourth tone up from the E first octave. Reaching its peak $\left(g_{3}\right)$, shivering and trembling, the sonority melts away within flageolet tremolo.

The original mix of sound production in the imitation of guitar, elegiac intonations and pentatonic scale can be seen in the piece of the same fifth cycle. The first part consists of the 
phrase repeated four times, which can be divided into two parts. In the first duple meter after the arpeggiato of the offbeat $g$-moll triad there is an ascending step into the minor sixths followed by the conjunct descent, which is a typical melodic idiom of Russian romance lyrics. In the second duple meter S. Gubaidulina rhythmically makes up the D minor pentatonic scale, decorating it with characteristic Tatar melismas. Thus, another symbol appears, in which two cultural worlds Russian and Tatar - are combined in a single musical phrase with their brightest features (Note sheet example 2).

Note sheet example 2. S. Gubaidulina "Tatar Folklore Inspirations", piece $V$ из from "Five pieces for bass domra and piano"
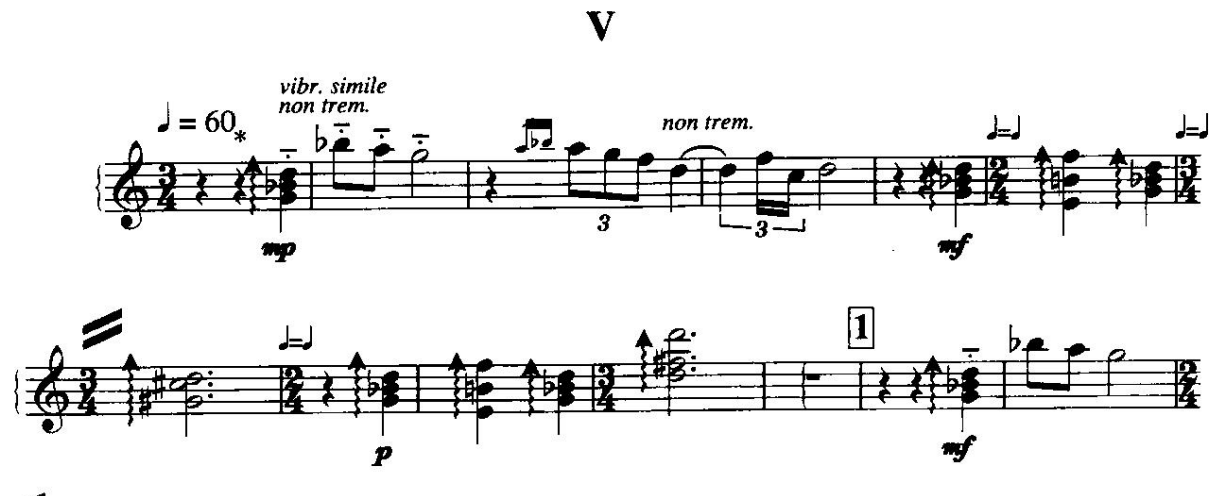

\section{The principle of polystylistics}

In scherzo pieces S. Gubaidulina uses the genres of so-called "light music", placing anhemitonic motives into jazz dance rhythms. These are the pieces numbered II in the first and the third cycles. It should be noted that S.Gubaidulina, who rarely refers to such allusions, uses the idea of "popular music", following Alfred Schnittke's musical-aesthetic paradigm, in which pop music genres were a symbol of evil in the art (see, e.g., "The hour of the soul"). But in this case, an appeal to the jazz style bears no infernal meaning. We could rather assume a purely technical interest of the composer to the fusion of sharp syncopated jazz rhythm and anhemitonic structures. The proof is in Gubaidulina's words. In one of the interviews, when asked about the fact what she receives from the light music, Sophia Asgatovna made the following confession: "I really like jazz. Louis Armstrong, Duke Ellington are great discoveries for me. When I see Armstrong with his pipe and hear the first sounds of it I come to the same ecstatically positive state as he did" (Polyakova S., 2007).

As we can see, this curiosity led to the acoustic result full of unusual discoveries. For example, in scherzo of the first cycle, the repetitiveness of motivic cell, which is inherent in dynamic jazz compositions and interspersed with sharp sounding of power chords with a split quint, turns into its opposite in the second part of the piece. Pentatonic scale, losing syncopated drive, is enclosed with blues harmonies - small minor and large major seventh chords - which degenerate into diatonic clusters, on the background of which the echoes of the first theme sound.

Part 4 of the second cycle is marked with a similar principle of organizing musical material. The piece begins with the motor ostinato $g-f$ stroke, which is accompanied by the hemiditon $g-b$ from time to time. This trichord can be called a motivic cell. Such a melodic structure is typical for the tak-mak genre. However, S. Gubaidulina leaves the rhythmic and 
metrical regularity, which is inherent in this type of tunes, by putting the motivic cell in a different number of cycles.

The piano part contributes to the destruction of the square structure: sharp-sounding fourth chords fall on different complete and incomplete parts of the bar. Subsequently, the interval structure of clusters is constantly changing, acquiring diatonic and chromatic side tones, while maintaining the intonation structure of the domra motif. This resembles bebop jazz, in which improvisation extended to the sphere of harmony rather than melody.

The second piece of the third cycle is written in the boogie-woogie style. Pentatonic motive of domra is accompanied by trenchant piano beats, accented dissonance of which emphasizes the modal structure of the theme (Note sheet example 3).

\section{Note sheet example 3. S. Gubaidulina "Tatar Folklore Inspirations”, piece II from "Five pieces for bass domra and piano"}

II

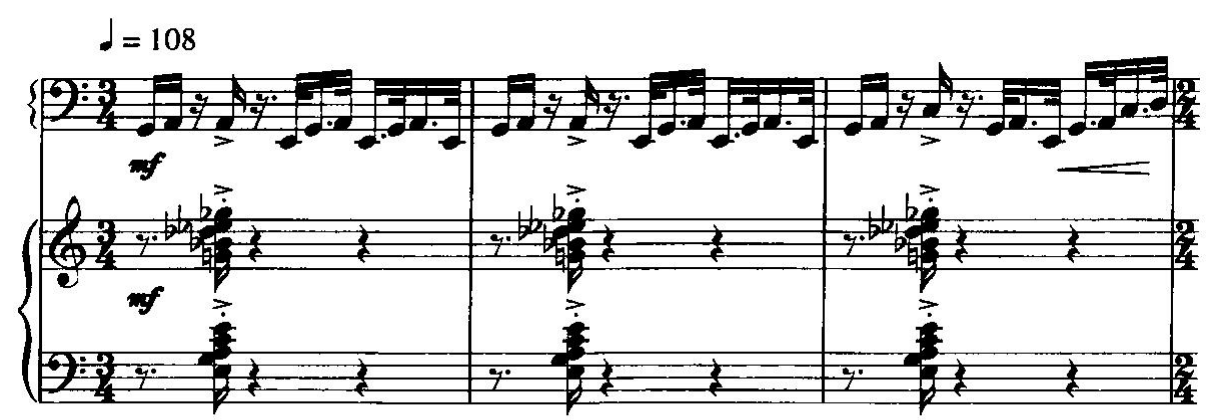

Gradually S. Gubaidulina modifies the given pentatonic "formula" by introducing chromatic sounds in it. In the second part of the piece the thematic cell loses its original modality - the composer leaves a characteristic dotted rhythm, surrendering to total chromaticism. Here S.Gubaidulina uses techniques borrowed from jazz - solo instruments (domra - grand piano domra), polyrhythm, fantasy passages on the chromatic scale, up and down domra glissando. The reprise represents the return of the pentatonic theme of the domra part, but, trying to keep the jazz style until the end, S. Gubaidulina finishes the part in a distinguished way - domra "hangs" on the dissonant sound (fis).

\section{The principle of chromatization}

Pentatonic occurs only in some fragments of the final two parts of the third cycle, giving the way to the chromatic atonality. The first fragment of part IV is built on the concentric development of a motivic segment within the "free twelve-tone system" (Dyachkova, 2003). We can assume it serves as a "central element" (Kholopov and Tsenova, 2007), in the context of the atonal organization of the material, being the "original intonation complex, which generates all the melodic and harmonic formations of the composition" (Dyachkova, 2003, p. 90). S. Gubaidulina represents the initial intonation construct in the vertical consonance Gis- $A$-es of domra, immediately "spreading" it to horizontal part for grand piano in the next bar. Then she adds $D$ sound to this motif. Thus the cohesion of two tritons - D-Gis and A-es - is formed. This 
intonation cell plays the role of such an element which will generate intonation transformations, built on gradual adding of chromatic sounds E, F, Fis, G, Gis to the tritone complex.

Gubaidulina's textured resolution of the second part of the piece resembles the combination melody + accompaniment. Anhemitonic melos in the grand piano part is accompanied by the chord "strumming" of domra.

The composer's preferential use of consonant harmonies, clear vertical delimitation of the components of the texture layer, the emotional intensity of sound caused by a dotted and syncopated rhythm, the sudden change of the tempo (half faster than the former) and the dynamics $(f f)$ - all this is in stark contrast to the previous episode, in which the gradual musical development, linear presentation of the material, chromatics and dissonance prevail.

In the third part there is the return of the original form of the music texture organization, but we may notice some changes. The hemitonic area expands significantly, covering almost the entire twelve-tone row. The starting intonation structure tritone +tritone is modified, acquiring the following form: the perfect fourth + tritone. The chromatic catabasis - "a tragic symbol of the descent" (Kozylov, 2010. p 54.) - prepares a concentrated and melancholic coda built on the intonation and texture inversion of the second part of the piece. The theme earlier used in the grand piano party passes to domra. The low register and even rhythm of the melody against the syncopated pulsation of chords of the piano accompaniment bring some gloomy colour to the sound. We can hear some echoes of Massenet's "Elegy" in the intonation structure and timbre colour of alto domra simulating the "voice" of the cello (Note sheet example 4).

Note sheet example 4. S. Gubaidulina "Tatar Folklore Inspirations", piece IV from "Five pieces for bass domra and piano"

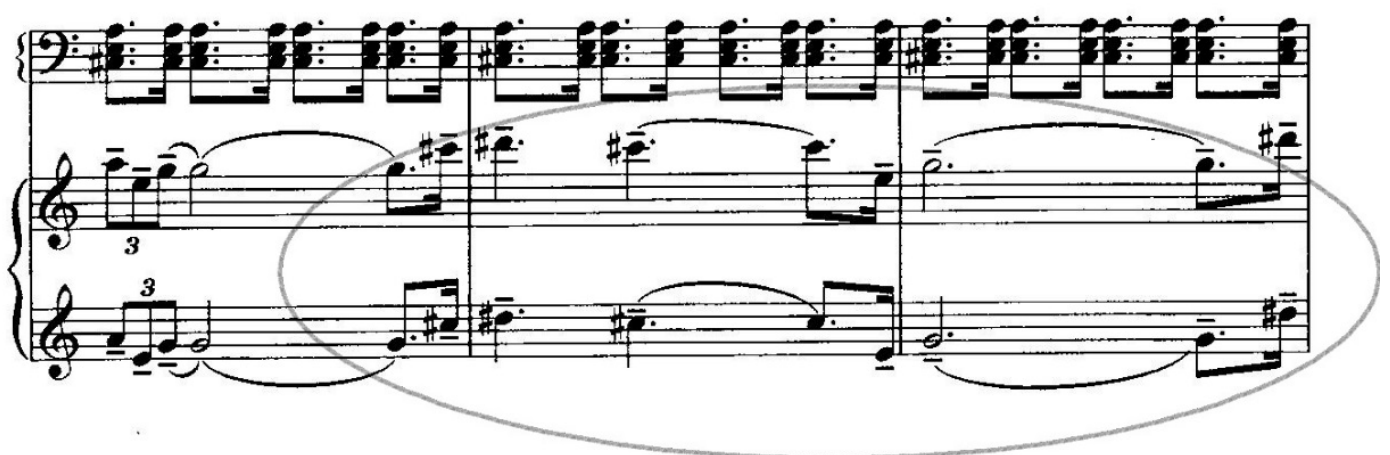

Gradually disappearing sonority prepares the final part of the third cycle. This finale has a pronounced eschatological colour. The glissanding "buzz" of domra depicts the "sounds of the wind in the cemetery" (quoted from: Mukhametdinova and Sokolskaya, 2013, p. 12). The other world is reflected in "the two planes of existence" in the grand piano party: the gradual descent of the minor triads deep into the bass diapason on the chromatic scale (again - catabasis!) is balanced by the chords flying into the crystal height of the upper register. According to S. Gubaidulina, these harmonies do not have "same sounds, and that is why there is gravity in each of them, which is settled in the opposite space" (quoted from: Mukhametdinova and Sokolskaya, 2013, p. 19). Thus, eidetic symbol appears: "the sound born on the earth" (quoted from: Mukhametdinova and Sokolskaya, 2013, p. 19.) is the reflected essence of a different - space world. 


\section{Conclusion}

Musical triptych "Tatar Folklore Inspirations" is an original fusion of different styles, in which the features of the Tatar folk music culture, tart sound of jazz, sonoristic methods of working with musical texture, elements of rock and ethnic music of other nations combine organically. Pentatonic sound, which permeates the whole cycle, represents here those protostructures which are demonstrated by the rootedness of Gubaidulina's music speech in the deep layers of ancestral memory. S. Gubaidulina's masterful introduction of pentatonic scale in the "verbal space" of panEuropean musical vocabulary allows us to refer Tatar Folklore Inspirations" not only to the works that demonstrate the features of the national school of composition, but also to rightfully consider this work as a model corresponding to the leading artistic phenomena of the time.

\section{Acknowledgements}

The work is performed according to the Russian Government Program of Competitive Growth of Kazan Federal University.

\section{Notes}

1. S. Gubaidulina was not alone in the aspiration for synthesis of musical traditions of the East and the West in her work. Interesting experiments on the introduction of characteristic intonations of Tatar folklore in the sound field of popular music, jazz, and even dodecaphony can be observed in the works of such Tatar composers as Rafael Belyalov (Khurmatullina and Salpykova 2014) and Shamil Sharifullin (Kovrikova and Nurgayanova, 2016), who became the classics of Tatar professional art of the $20^{\text {th }}$ century.

2. The variety of struck stringed musical instruments such as the lute, which is widespread in the Arab countries.

3. The composer puts the remark - "Imitating the sound of the guitar".

\section{References}

Aranovskiy M.G., 1998. Musical text. Structure and features. Moscow, Kompozitor Publ., pp: 341.

Basharova I.R., 2008. Semantic organisation of Sofia Gubaidulina's instrumental music for children, Dr. ped. sci. diss., Ufa State Institute of arts.

Dyachkova L.S., 2003. Harmony in the music of the $20^{\text {th }}$ century. Moscow, RAM im. Gnesinykh Publ., 2003, pp: 296.

Gan’ B., 1997. Typification of Oriental perception in the music of S. Gubaidulina Moscow, pp: 47.

Gubaidulina S. Tatar Folklore Inspiration [Audio recording] // YouTube. June 5 2016. Date Views 04.08.2017 https://www.youtube.com/watch?v=Z6fCfhoocmE

Kholopov Yu.N. and Tsenova V.S., 2007 Harmony. Pitch Structure. Modern Composition Theory. Moscow, Music: 122-163.

Kholopova V.N., 1991. Stylistic Specifics of S. Gubaidulina's Music and Her Third Quartet. Music Composition Poetics. In the Proceedings of the Proceedings of the Gnesins State Musical and Pedagogical Institute. Iss. 113. Moscow, pp. 32-50.

Kholopova V.N., 1999. Sofia Gubaidulina and Oriental Avant-Garde: Correlations. Music of the $20^{\text {th }}$ century. In the Proceedings of the 1999 Moscow Forum. MGK im. P.I.CHaykovskogo, pp: 153-160. 
Kholopova V.N., 2015. Russian Classical Music of the Last Third of the $20^{\text {th }}$ Century and Early $21^{\text {th }}$ Century. Genres and Styles. Moscow, 2015. pp. 226. Date Views 06.09.2016 http://www.kholopova.ru/Russian Academic Music (Genres and Styles).V.Kholopova.pdf

Khurmatullina R.C. and Salpykova I.M., 2014. Tatar folklore in the creative work of composer Rafael Belyalov. Middle-East Journal of Scientific Research, 19 (1): pp. 29-41.

Kovrikova E.V. and Nurgayanova N.Kh., 2016. Spiritual musical and cultural traditions of the tatars in the music of Shamil Sharifullin. In the Proceedings of the 2016 III International Multidisciplinary Scientific Conference on social sciences and arts 2016. Volume III: pp: 63-70.

Kozylov A.S., 2010. Alfred Dezenklo "Prelude, cadenza and finale" for saxophone and piano. Interpretation specifics. Current Problems of Higher Music Education, 2: 53-55.

Kudryashov A.Yu., 1990. Modal and Harmonic Features of S. Gubaidulina's "The Garden of Joy and Sorrow”. Musicology Problems. Music. Language. Tradition. Leningrad, LGITMiK Publ., 5: 179-192.

Lochhead J., 2015. Reconceiving structure in contemporary music: New tools in music theory and analysis , Music Department, Stony Brook University, pp: 1-179.

Monasypov Sh.Kh., 2014. Spiritual and Scientific Portraits of the Outstanding Artistic Personalities of Tatarstan. Kazan: Kazanskaya gos.konservatoriya Publ., pp 320.

Mukhametdinova G.F. and Sokolskaya YU.YU., 2013. Methodological and performance recommendations for S. Gubaidulina's three cycles of pieces "Tatar Folklore Inspiration"Sofia Gubaidulina: The Sound of the Unknown. Kazan, Kazanskaya gos. konservatoriya Publ., pp. 82.

Neary F. D., 1999. Symbolic structure in the music of Gubaidulina. Dr of Musical Arts diss., The Ohio State University.

Polyakova S., 2007. Sofiya Gubaydullina: The Sound of the Unknown. New Gazette. Date Views 06.09.2016 http://www.novayagazeta.ru/arts/3720o.html 